\title{
O CORPO HUMANO COMO ALIMENTO PARA A SEXUALIDADE
}

\author{
HUMAN BODY AS A FOOD FOR SEXUALITY
}

\author{
Everton Luiz de OLIVEIRA ${ }^{1}$ \\ Daniel Cordeiro CARDOSO ${ }^{2}$ \\ Fátima Elisabeth DENARI ${ }^{3}$
}

\begin{abstract}
RESUMO: O presente artigo retrata uma caminhada teórica com vistas à enunciação de uma narrativa histórica e cultural que apresenta o corpo como elemento central na formatação e construção da sexualidade humana. Tal caminhada intui evidenciar algumas projeções, pensamentos e materializações que permitiram definir a beleza corporal como promotora de desejos, intencionalidades e sensações eróticas em favor de uma sexualidade anunciada no e pelo senso comum como ideal. Objetivou-se, ainda, problematizar a maneira como a estética físico-corpórea tem servido de mola propulsora para a configuração de discursos cristalizados sobre a sexualidade, falseando a ideia de que apenas os corpos alinhados com os modelos corporais hegemônicos podem ser considerados objeto de desejo, prazer e de práticas sexuais e eróticas. Por fim, apreende-se que o corpo também pode ser admitido como instrumento capaz de subverter a lógica preestabelecida em que: corpo, beleza e práticas sexuais parecem formar uma tríade em favor do mito da sexualidade perfeita ou performática, na medida em que os corpos (todos eles) sejam reconhecidos pela coletividade como promotores de prazeres, desejos e sustentáculo para práticas afetivas e rotinas sexuais/eróticas, independentemente de suas formatações fisiológicas, anatômicas e estéticas.
\end{abstract}

PALAVRAS-CHAVE: Corpo. Educação sexual. Sexualidade. Estética. Beleza.

ABSTRACT: The present article depicts a theoretical walk, based on a historical and cultural narrative, that presents the body as a central element in the formatting and construction of human sexuality. Such walk intuits to show some projections, thoughts and materialization which ascertained the physical beauty as a promoter of desires, intentions and erotic feelings, in favor of an announced sexuality and common sense as ideal. The objective was also discuss, how the physical body aesthetic has been the driving force for configuring standard discourses on sexuality, distorting the idea that only the similar bodies to the hegemonic body models can be considered as object of desire, pleasure, and sexual and erotic practices. Finally, it learns that the body can also be admitted as an instrument to subvert the predetermined logic that body, beauty and sexual practices appear to form a triad in favor of the myth of perfect or performative sexuality. As the bodies (all of them) has been recognized by the community as promoters of pleasures, desires and foundation for effective practices and sexual/erotic routines, regardless of their physiological, anatomical and aesthetic formatting.

${ }^{1}$ Centro Universitário UNIFAFIBE, Bebedouro - SP - Brasil. E-mail: oliveira-everton@ hotmail.com.

${ }^{2}$ Universidade Estadual Paulista (Unesp), Faculdade de Ciências e Letras, Araraquara - SP - Brasil. Mestre pelo Programa de Pós-graduação em Educação Sexual. E-mail: nelccard@yahoo.com.br.

${ }^{3}$ Universidade Federal de São Carlos (UFSCar), Centro de Educação e Ciências Humanas, São Carlos - SP Brasil. Professora do Departamento de Psicologia. E-mail: fadenari@terra.com.br. 
KEYWORDS: Body. Sexual Education. Sexuality. Aesthetics. Beauty.

\section{Primeiras palavras...}

A partir da compreensão da multiplicidade de dinâmicas analíticas e interpretativas que emanam do universo da sexualidade, destaca-se a importância do esforço de desvendar facetas e materializações sociais, afetivas e humanas que se encerram no corpo, no corpo que serve de estandarte e palco para a sexualidade. Desta feita, importa neste momento deslocar olhares para os componentes e perspectivas anatômicas e físicas do corpo, na tentativa de demonstrar seu lugar de destaque na formatação da sexualidade e do universo erótico que circunscreve a vida social e afetiva das pessoas.

O erotismo é indissociável do universo da beleza, na medida em que os conceitos de belo e de beleza que se formam a partir da subjetividade humana dão os contornos e servem de base para a expressão do erotismo e do desejo. Nessa compreensão, "não podemos falar no erótico, lato sensu, se não nos referirmos à beleza" (ASSUNÇÃO JUNIOR, 2008, p.8), tendo a compreensão de que a apreensão e/ou conceito de beleza que se forma na subjetividade humana, é definidora de vontades e desejos no campo da sexualidade e, inegavelmente, do erotismo.

Garton (2009) destaca a necessidade de levar em consideração a ideia de que o desejo é caracterizado por orientações que se diferenciam em determinados grupos de pessoas, gerando tipos particulares de desejos. Portanto, o objeto de desejo de cada pessoa no que tangencia sua sexualidade pode ser distinto e modificável de acordo com a cultura, tecido social e econômico ou período histórico em que se encontra.

Embora o presente foco de análise incida sobre a sexualidade, dar-se-á destaque às contribuições de Mauss (1974), precisamente quando externa que no decorrer dos períodos históricos, os homens fizeram inúmeros usos do corpo, definindo-o como um instrumento universal, na medida em que as culturas ao sabor dos acontecimentos e vontades, acabaram disciplinando, moldando e educando os corpos da coletividade.

Porém, ressalta-se que o objeto de desejo que nos interessa como lócus de investigação no contexto da sexualidade define-se no e pelo corpo físico, esta estrutura estética e anatômica que carrega uma bagagem simbólica, delineada histórica e culturalmente, refletindo buscas e anseios construídos no decorrer das práticas, vivências e relações acumuladas cotidianamente. 
Garton (2009) enfatiza que são desejos e as diferenças sexuais que movem e transformam a sexualidade e se voltam, em uma proporção incalculável, para o corpo e sua condição modificável, seja pela fisiologia/anatomia ou pela realidade cultural e social circunscrita.

O corpo belo e desejado estética e sexualmente tem vida própria, no sentido de que não estaria necessariamente dependente de valorizações, gostos e sabores metamorfoseados nas e pelas distintas sociedades e povos ao longo dos tempos. A beleza chega e se apresenta, a beleza excita, toca e comove o olhar, desperta uma admiração instantânea e provoca os sentidos e o interior daquele que com ela se encontra.

Se antes o corpo era visto por alguns teóricos do construtivismo social como entidade neutra e indiferenciada, compondo depois uma identidade histórica específica, para outros teóricos ligados ao feminismo e ao movimento LGBT, corpo e desejo são forjados socialmente e têm uma base material; onde forças sociais e linguagem modificam comportamentos e atitudes a partir da transformação de entidades materiais (GARTON, 2009). Nas sociedades ocidentais as concepções de beleza vão ao encontro das formas e estruturas físico-corpórea: possuir uma bela face e um corpo magro e escultural tornaram-se prerrogativas para se ostentar uma beleza admirável. Aquilo que apreendemos como mais desejável no outro é, invariavelmente, aquilo que percebemos como bonito/belo, levando à vontade de se unir sexualmente com as pessoas mais próximas da perfeição (MARWICK, 2009).

No entanto, a filosofia grega, preconiza a concepção da beleza física associada inicialmente à virtuosidade, no sentido de que a beleza estética, moral e espiritual era relacionada a elementos puros, estes qualitativamente concebidos por meio dos sons e cores agradáveis, das figuras geométricas regulares, das formas abstratas, sendo tais elementos, portanto, reduzidos a dois princípios: o equilíbrio e a unidade na variedade, ou seja, simetria e singularidade unidas em um só elemento; seria Belo (to kalón), portanto, toda a singularidade que agrada ver e ouvir, resultando assim em prazer superior de estado de alma, diferente do gozo físico, que levaria à insatisfação permanente e aos desequilíbrios das paixões (NUNES, 2009).

A concepção filosófica da beleza física, portanto, diverge substancialmente da beleza física concebida atualmente, pois era, segundo Nunes (2009), correlacionada à índole moral. Tal fato é ilustrativo quando o referido autor cita Platão, quando determinava aos jovens de sua república que praticassem exercícios físicos para terem seus corpos harmoniosos juntamente com atividades de ordem artística, unindo assim a beleza estética (corpo) e a 
adequação na beleza moral (música, poesia). Esta segunda espécie de beleza, a moral, de acordo com os gregos, serviria para acalmar as paixões, predispondo assim o jovem à práticas de virtudes (NUNES, 2009).

Pode-se apreender a beleza física contemplada em culturas antigas, projetada e narrada na mitologia grega e no renascimento. Na renascença, a beleza relacionada ao erótico pode ser observada em afrescos, telas e esculturas, retratada por meio de algumas nuances padronizados/valorizados à época, tais como: mulher de seios pequenos e barriga saliente, o olhar, sugerindo um magnetismo para o ato sexual, como exemplificado na obra Vênus de Urbino, do pintor italiano renascentista Ticiano. Na mitologia, a lenda grega do disforme Hefesto, o deus trabalhador do panteão grego, há o relato de que este deus, retratado como feio e coxo, teria sido diversas vezes traído por Afrodite, sua esposa, com o deus Ares. Tal relato pressupõe que havia, já na cultura clássica, a dicotomia entre o feio e o belo (POUZADOUX, 2001).

$\mathrm{Na}$ atualidade, a beleza passou a ser definida por atributos essencialmente físicos, evidenciando-se a imersão em um espaço em que o corpo torna-se mediador para todos/as aqueles/as que anseiam entrar em um universo sensualista cada vez mais cotejado por uma estética corporal performática, simétrica e estruturalmente moldada.

Nesta caminhada, tem-se a valorização e erotização a partir da topografia corporal, colocando em com destaque de um espaço para exaltação e reificação dos modelos de beleza física, cultural e socialmente reconhecidos no e pelo imaginário coletivo como belo autêntico, definindo-se limites para aquilo que entender-se-á como belo/beleza (corporalmente) tanto para homens quanto para mulheres (PEREIRA, 2000).

\section{Beleza física e sexualidade nos interditos da sociedade de consumo}

As projeções e contemplações que se faz atualmente sobre beleza desvincularam-se em algum grau das noções de moral e espiritualidade. No concernente àquilo que se identifica atualmente como beleza física padronizada, considera-se que a sua ausência torna-se difícil de ser aceita pelo indivíduo, isto é, quando os apelos deste imperativo atinge a subjetividade deste, sente-se deste modo inadequado com seu próprio corpo, uma vez que a aparência pessoal tem relação com o sentimento de valor próprio e, indiscutivelmente, com a sexualidade, a atração e ao sucesso sexual de cada um. A beleza estaria associada ao prazer sexual, uma estética encantadora que promoveria o fascínio pela busca da satisfação sexual (MARWICK, 2009). 
Não se sentir belo ou ser julgado como tal pode impelir a um sentimento de ofuscamento ou obliteração da sexualidade, afastando as pessoas das buscas e conquistas no campo do prazer e das práticas sexuais e eróticas por não se sentirem desejadas, cobiçadas ou atraentes. A partir deste viés estético corporal, sentir-se belo ou creditar beleza ao outro, pode exercer influência estreita na maneira como cada um configurará a sua sexualidade e seus comportamentos sexuais (NOVAES, 2008).

Neste sentido, a beleza física (tanto no homem como na mulher) configura-se como uma qualidade ou virtuosismo que não deixamos de notar, oferecendo ao seu possuidor uma copiosa oportunidade sexual (sugerindo inclusive promiscuidade, luxúria e voracidade carnal), afastando-se de qualquer compreensão compatível como a noção espiritualizada do significado da beleza (MARWICK, 2009).

A beleza humana que se anunciada por meio da estética e da anatomia físico-corpórea, indiscutivelmente, revela modelos e padrões corporais hegemônicos forjados cultural e socialmente, corpos perfeitos que mesmo não servindo de garantia para a felicidade e a satisfação sexual, exercem influência na escolha dos parceiros sexuais e na construção dos relacionamentos afetivo-sexuais. Contudo, é de se esperar que o mito do corpo perfeito atormente muito mais os jovens (inseguros no ritual da conquista, com conflitos de autoestima e desconhecedores de sua sexualidade e de seu parceiro) do que os adultos (FURLANI, 2009).

Queiroz e Otta (2000) atestam que a beleza física também apresentaria relação direta com a realidade socioeconômica de cada grupo social, admitindo-se que nas classes com menor renda a beleza não exerceria forte influência nas objetivações, relacionamentos e práticas sociais; em contrapartida, quanto mais elevada a condição econômica e financeira dos grupos, invariavelmente, maior também é a cobrança por deter uma beleza digna de ser contemplada, valorizada e reconhecida. Neste sentido, a beleza corporal nas sociedades modernas é traduzida como sinal de poder aquisitivo elevado, enquanto sobre os considerados feios recai sempre a suspeita de que sejam pobres. Observa-se assim "[...] corpos capazes de expressar e exibir os signos, as normas e as marcas corporais da sociedade industrial evidenciando, inclusive, as distinções de classe." (GOELLNER, 2003, p. 37).

Ademais, na perspectiva de uma sociedade industrial consumista, a beleza física apresenta-se atualmente como o produto mais desejável. A cultura de massa, representada pela indústria cultural vigente, apresenta por variados veículos midiáticos imagens/situações eróticas que, ao mesmo tempo em que se promete a possibilidade de tornar-se ser belo/a e sair realizando seguidas conquistas sexuais, não se cumpre tal promessa, por razões óbvias no tocante da realidade cotidiana de cada um (ADORNO, 1999). 
Em contrapartida, a indústria cultural dá passe livre ao consumo de produtos que substituem a conquista para o ato sexual em si, dando a ideia aos consumidores de uma legitimidade e um pertencimento em direção a um grupo seleto de pessoas tidas como belas (ADORNO, 1999). A título de exemplo, possuir ou desenvolver um determinado signo cuja conotação atual seria erótica (roupa, fala, gesto, tipo físico, etc.), tal qual a personagem que, em cenas sensuais estaria exibindo na telenovela, daria a sensação, na subjetividade de alguma consumidora incauta, de que ela seria "para sempre" uma conquistadora sensual em potencial, caso se apropriasse dos mesmos signos.

Esta artimanha da sociedade industrial moderna em associar diretamente desejo sexual e consumo, levaria à repressão da real liberdade das pessoas enquanto sujeitos ontológicos, no sentido de que elas se apartariam do conceito de beleza estética primordial, que a cultura ocidental herdou dos gregos. Ignorando tal herança, e já sem liberdade, o senso comum entende como prerrogativa principal a aquisição (urgente) da maioria do material oferecido pela indústria cultural. Esta, por sua vez, utiliza de seu instrumental midiático uma nova forma de controle, em que

[...] independência de pensamento, autonomia e direito à oposição política estão perdendo sua função crítica numa sociedade que parece cada vez mais capaz de atender às necessidades dos indivíduos através da forma pela qual é organizada. Tal sociedade pode, justificadamente, exigir a aceitação dos seus princípios e instituições e reduzir a oposição à discussão e promoção de diretrizes alternativas dentro do "status quo" (MARCUSE, 1982, p. 23-24).

Neste sentido, Marcuse (1982) incita-nos à abertura de questionamentos relativos às pseudo-necessidades que a sociedade industrial imprime nas dinâmicas e projeções que se estabelecem mediante o alicerce do senso comum, e este por sua vez, tenta irrefletidamente sanar, em um jogo incessante, tais necessidades. Em concordância com Adorno (1999), que elucida: "a indústria cultural não sublima o instinto sexual, como nas verdadeiras obras de arte, mas o reprime e o sufoca", ou seja, quanto mais o corpo é considerado pelas massas como objeto de consumo, mais estaria o sujeito distante de sua própria condição ontológica de liberdade.

Segundo Goellner (2003) o desnudamento do corpo que anuncia sua exposição e desfila no palco público, promovendo corpos enxutos e "em forma" onde o excesso, mais que rejeitado, é visto, por vezes, como resultado da displicência e da falta de cuidado. A responsabilidade pelo corpo, pela beleza que cada um possui ou deixa de possuir recai, 
exclusivamente, sobre cada pessoa em particular: cada uma é entendida como empresária da sua própria aparência (COUTO, 2003).

O fenômeno de culto ao corpo ${ }^{4}$ iniciou uma guerra contra as rugas, gordura e os volumes indesejados: a remodelagem e a modificação corporal são festejadas na medida em que se defende a ideia de que o corpo deve trocar, reconfigurar, descartar e reconstruir as "partes defeituosas", substituindo-o por uma versão anatômica adequada a cada ocasião ou performance (COUTO, 2003).

Ao avançar nas discussões sobre beleza e sexualidade, pode-se destacar que uma das razões que influenciam muitas mulheres e, em particular, aquelas com problemas de obesidade, a se sentirem feias, compromete-se com o fato de não se sentirem atraentes, sexies, desejadas, cobiçadas e olhadas pelo sexo oposto. No extremo oposto estariam as jovens adeptas da malhação, dispostas a apresentar seus corpos para o julgamento coletivo, algo a ser admirado, elogiado, representando valiosa associação com a atividade sexual (NOVAES, 2008).

Para Furlani (2009) o sistema capitalista ao legitimar seu sistema econômico imputa o comportamento consumista, corroborando inclusive para a compreensão do corpo como objeto ou mercadoria. Advoga-se que o corpo perfeito, esbelto e atlético seria elemento nuclear nas e para as relações sexuais satisfatórias, nas quais atuariam como mecanismos de atração e desejo. No ideário que se propaga pelo senso comum, o mito do corpo perfeito, também poderia conduzir a outro mito, igualmente equivocado, o mito da performance individual, cuja ideia motriz seria a de que ser "bom de cama" significaria conseguir ficar mais tempo (ou aguentar mais) ou conseguir "mais vezes" numa noite.

Nas palavras de Zuin (2003), evidencia-se que a necessidade de ter que impressionar seria um imperativo categórico desta sociedade espetacular para que o sujeito possa existir, sentir-se parte integrante do tecido e das relações sociais. Ainda, nessa sociedade espetacular o ato de impressionar, ser notado, sentido da e para a existência, excitaria mais do que a consumação da própria relação sexual.

\footnotetext{
${ }^{4}$ A ideologia que se vende aos adeptos do culto ao corpo é que o indivíduo, ele e somente ele é quem vai prestar contas ao olhar crítico e hierarquizante de seus pares, além de se submeter ao escrutínio da fita métrica, da balança e do espelho em um processo que exige dele uma conduta ascética, racional e individualista. E mais, além de ser produto do esforço individual, passa pela conquista de um corpo que só ele vai ter e, posteriormente, da forma física como veículo de afirmação de status, conquista de parceiros sexuais em mesmo nível estético e inserção social (BERGER, 2006, p. 140).
} 
$\mathrm{Na}$ atualidade, a beleza física, particularmente, aquela que coaduna com os modelos estéticos hegemônicos ${ }^{5}$, tem estreita relação com a construção de uma sexualidade histórica e culturalmente forjada a partir da validação e naturalização de determinados modelos corporais, reconhecendo os "corpos válidos" $"$ para as práticas sexuais e eróticas, reforçando estigmas e preconceitos que recaem sobre aqueles corpos considerados feios, estranhos, anômalos, obesos, flácidos, disformes e assimétricos.

Na contramão dessas proposições tem-se a importância de reconhecer o corpo como receptáculo de forças e ideias capazes de subverter as projeções que incidem sobre a sexualidade humana, destacando que os paradigmas materializados no encontro entre beleza, corpo e sexualidade podem ser superados na medida em que a coletividade compreender que o "[...] mais importante não é exatamente o tipo de corpo que temos, mas aquilo que podemos fazer com ele, com seu potencial de sedução e com a capacidade de torná-lo suficientemente erótico e sensual ao prazer e à satisfação sexual e afetiva.” (FURLANI, 2009, p.30).

\section{O corpo no cardápio das relações e práticas sexuais}

Loyola (1999) defende o corpo humano como sede da sexualidade e o sexo como sendo o palco das formatações e constructos ideológico e de poder que regem a vida na contemporaneidade (mantendo-se a trilha de outros períodos históricos).

Pode-se imaginar, ao menos timidamente, o impacto que o projeto de esculturação e performance do corpo acabou exercendo nas vontades e desejos sexuais e eróticos da coletividade; corpos rígidos, fortalecidos, remodelados, cujos "donos" abnegam de tempo e dinheiro para não serem identificados como malogrados sujeitos que sequer podem ser objeto de desejo e de contemplação de outrem, atestando que ser belo configura uma urgência no empreendimento de relacionamentos e praticas sexuais.

Essa busca pela performaticidade e melhoria estética do corpo também pode ser colocada na esteira do atual processo de significação da sexualidade, na medida em que se considera um panorama no qual se confrontam duas lógicas: uma que converge para o esforço de maximização da vida e outra (esta que nos interessa) que incide sobre a otimização do corpo como fonte de prazer (ênfase na intensidade) (HEILBORN; BRANDÃO, 1999).

\footnotetext{
${ }^{5}$ Segundo Berger (2006) esses modelos corporais ou arquétipos de beleza, na atualidade, caminham entre o corpo magro (para as mulheres) e o corpo "sarado" ou musculoso (para os homens), ambos jovens.

${ }^{6}$ Expressão originalmente utilizada por Virilo para se referir ao modelo corporal reconfigurado e superequipado por próteses teleinformáticas e biotecnológicas, promovendo melhorias e avanços em prol da beleza, juventude, performance e vitalidade (COUTO, 2003).
} 
Ao assumir que “[...] o corpo material cria os horizontes físicos e anatômicos para corpos e prazeres, que impõem limites à gama de expressões disponíveis para aquilo a que se chama sexualidade" (GARTON, 2009, p.55), poder-se-ia indagar até que ponto e de que forma um corpo e sua materialidade poderiam de fato projetar os horizontes da sexualidade e de sua proeminente história.

Goldenberg (2008) observou que as referências ao corpo denotam a importância e centralidade conferida tanto no tocante à construção da sexualidade, quanto na formação de uma identidade e reconhecimento social a partir da beleza e estética corporal.

Neste ponto, pode-se reter como lócus de análise e reflexão o corpo caracterizado pelo acúmulo de gordura, aquele definido por grandes dimensões e/ou volumes de tecido adiposo, comumente definido como corpo gordo ou obeso, evidenciando percursos históricos onde desfilou ora como belo e receptáculo de signos de poder e status, ora como abjeto e, ainda, campo estético para definição do feio/feiura.

Admite-se assim que a gordura configuraria, na atualidade, um dos principais paradigmas da feiura, evidenciando preconceitos e discriminações de uma sociedade que cultua o corpo, aquele do tipo escultural, hipertrofiado e "enxuto". Neste sentido, vale ressaltar que estamos diante de um tipo de discriminação ostensiva manifestada sem culpa pela coletividade (NOVAES, 2005).

Ao assumir que a percepção e as expectativas que uma pessoa tem de outra, sendo essas favoráveis ou não, acabam condicionando a maneira como cada uma se posicionará nas práticas e relacionamentos sociais sem que os próprios envolvidos percebam, apreende-se que a aparência, indiscutivelmente, desempenha papel importante neste processo interativo (QUEIROZ; OTTA, 2000).

No tocante à sexualidade, Novaes (2008) adverte sobre a frequência com que muitas pessoas que acumulam grandes níveis de gordura se queixam de não se sentirem satisfeitas com sua sexualidade, expressando poucas referências a qualquer tipo de atividade sexual. Neste sentido, é salutar compreender que não apenas o corpo tem sido objeto de classificação e valorização, mas, e, principalmente, suas partes e estruturas, que se encontram no seio de um processo de hierarquização e reconhecimento social, cultural e histórico.

A partir das palavras de Pereira (2000) pode-se fazer referência ao universo simbólico criado a partir da geografia ou espaço corporal, definindo quais as áreas proibidas e não proibidas, belas e feias, valorizadas ou desqualificadas, atraentes ou pouco importantes, gerando todo tipo de sentimento em sinergia, dentre outras coisas, com a beleza e a sexualidade. 
Na extensão desta compreensão, a erotização do corpo e a construção da sexualidade teriam relação estreita com a topografia corporal, sendo esta "[...] formada por relevos, planícies e fendas, como os seios, o ventre, os órgãos sexuais, as nádegas. É a geografia dos planos, dos côncavos e dos convexos" (PEREIRA, 2000, p.78).

Não obstante, torna-se recorrente a constatação de que os volumes e regiões físicocorpóreas têm sido hierarquizados e valorizados no decorrer dos períodos históricos de acordo com diferentes grupos sociais e culturais, marcando singularidades e corporeidades que muito mais do que projetos corporais estéticos revelam ideologias, relações de poder, conflitos religiosos, preceitos fílosóficos, antropológicos e econômicos.

No que concerne às sociedades regidas pelas relações de produção e de poder do modelo econômico capitalista observa-se que o corpo foi espetacularizado, na medida em que impressionar significaria existir, ser notado/a tornou-se imperativo categórico nas relações e práticas sociais. O processo de publicização do corpo anuncia a construção do desejo coletivo pela beleza e perfeição das formas anatômicas, mesmo que ainda esteja presente a consciência inquietante de que somos mercadorias facilmente substituíveis (ZUIN, 2003).

Entre os seios destacados sobre uma silhueta em "S" marcada pelo uso do espartilho na Belle Époque (triunfando a mulher-flor) e a beleza andrógina de um corpo magricelo como o da atriz e modelo Kate Moss (FAUX et al., 2000), o abdômen enrijecido como um pedaço de ferro (ZUIN, 2003) e os glúteos avantajados (PEREIRA, 2000) parecem formar junto um duo a partir desta geografia corporal que retém o interesse e apetite sexual em terras tupiniquins.

Na cultura popular a associação entre as partes do corpo humano e os alimentos que satisfazem nossas necessidades energéticas não é novidade, tampouco matéria de esquisitice, estando presente nos discursos, objetivações e práticas da vida social. Desta maneira, seios que viram melões e mamões, pênis que se materializam em salsichas, salames e linguiças, ânus confundido com rosquinhas, barriga de pudim e vaginas do tipo "esfirra de carne" são alguns exemplos do universo simbólico pelo qual desfilam os segmentos corporais, recebendo pesos valorativos ou depreciativos mediante a aproximação com determinados tipos de substrato alimentar.

Uma mulher ou homem rotulado como possuindo um corpo ou perfil do tipo "filé mignon" (QUEIROZ; OTTA, 2000), por exemplo, caracteriza-se como sendo aquela/e cuja estrutura corporal e/ou algumas partes específicas do seu corpo possuem a qualidade, valor e a primazia que são comuns às carnes nobres, aquelas detentoras de valiosas qualidades 
organolépticas, cujos atributos impressionam os órgãos dos sentidos e, dentre esses, destaque para a maciez.

Talvez e, apenas talvez, a busca pela redução de gordura corporal, impulsionada pelo medo da ingestão de gorduras ou alimentos altamente calóricos, associada à ingestão de bloqueadores de gordura, esteja promovendo, de maneira objetiva ou subjetiva (discreta ou oculta), a busca por parceiros sexuais e afetivos com baixo peso corporal, com corpos magricelos, com pouca ou quase nenhuma gordura corporal. Desta forma, indagar-se-á se ao optarmos por alimentos menos gordurosos, diets, não estaríamos também, invariavelmente, fazendo a opção por "pessoas diets", com pouca ou nenhuma gordura?

Por fim, sem a pretensão de oferecer respostas que possam atender com pontualidade a indagação supracitada, faz-se importante ressaltar que aquelas pessoas que detém corpos que coadunam com os modelos idealizados de beleza e estética hegemônicos têm sua geografia corporal prestigiada, valorizada e muitas vezes associada simbolicamente a determinados tipos de alimentos e, indiscutivelmente, acabam despertando sentimentos, desejos e sentidos que podem ser facilmente identificados em discursos, comentários e frases que cotidianamente desfilam pelos grupos, lugares e tempos da vida social e afetiva; tais como: "Olha que gostosa/o", "Você é uma delícia", "Vou te comer!", "Se pudesse eu te devoraria" e outras que recheiam o universo erótico e sexual do imaginário coletivo e/ou senso comum.

\section{Comentários finais}

Torna-se urgente a crítica que incida sobre esse estado de coisas na esperança de que a ideologia do corpo que se transforma em publicidade ambulante seja, enquanto ideologia, suscetível à desarticulação e desestabilização de suas proposições, evidenciando aquele que entender-se-á como mais valioso e custoso esforço.

O fato de que as consequências negativas da indústria cultural atualmente sobreporemse à dimensão humana, e considerando que há uma deturpação coletiva da representação estética e erótica dos corpos que ora se apresentam, este ensaio levanta questionamentos acerca do que seria o belo, no sentido lato do próprio termo.

De maneira análoga, há que se considerar de que o ser humano ainda não consegue vivenciar a sua sexualidade sem que tenda a associá-la a algo que lhe dê um significado. Tal significado, no entanto, sendo variável em cada cultura, é valorizado historicamente a partir da importância de sua representação coletiva. Sabe-se que o alimento sempre possuiu um peso 
significativo para o homem e suas relações. O sexo, por sua vez, carrega consigo uma enorme complexidade representativa, sendo assim concebido pelo homem de forma multifacetada.

No entanto, o presente ensaio oferece pequenas reflexões e problematizações que giram em torno da temática do corpo face à sexualidade humana, bem como das práticas e desejos sexuais.

Devido à enorme complexidade e amplitude do tema proposto, sugere-se outras análises e escritos acerca do mesmo que possam contribuir com os posicionamentos ora expressos neste ensaio.

\section{REFERÊNCIAS}

ADORNO, T. W. Adorno. São Paulo: Nova Cultural, 1999. (Os pensadores).

ASSUNÇÃO JUNIOR, F. B.; ALMEIDA, T. Sexualidade, cinema e deficiência. São Paulo: LMP, 2008.

BERGER, M. Corpo e identidade feminina. 2006. 312f. Tese (Doutorado em Antropologia Social) - Universidade de São Paulo, Faculdade de Filosofia, Letras e Ciências Humanas, São Paulo, 2006.

COUTO, E. S. Corpos modificados: o saudável e o doente na cibercultura. In: LOURO, G. L.; NECKEL, J. F.; GOELLNER, S. V. (Org.). Corpo, gênero e sexualidade: um debate contemporâneo na educação. Petrópolis: Vozes, 2003. p.172-186.

FAUX, D. S. et al. Beleza do século. Tradução de Paulo Neves. São Paulo: Cosac \& Naify, 2000.

FURLANI, J. Mitos e tabus da sexualidade humana: subsídios ao trabalho em educação sexual. 3.ed. Belo Horizonte: Autêntica, 2009.

GARTON, S. História da sexualidade: da antiguidade à revolução sexual. Tradução de Mário Félix. Lisboa: Estampa, 2009.

GOELLNER, S. V. A produção cultural do corpo. In: LOURO, G. L.; NECKEL, J. F.; GOELLNER, S. V. (Org.). Corpo, gênero e sexualidade: um debate contemporâneo na educação. Petrópolis: Vozes, 2003. p.28-40.

GOLDENBERG, M. Nem toda brasileira é bunda: corpo e envelhecimento na cultura contemporânea. In: CASOTTI, L.; SUAREZ, M.; CAMPOS, R. D. O tempo da beleza: consumo e comportamento feminino, novos olhares. Rio de Janeiro: Senac Nacional, 2008. p. $124-143$.

HEILBORN, M. L.; BRANDÃO, E. R. Introdução: ciências sociais e sexualidade. In: HEILBORN, M. L. (Org.). Sexualidade: o olhar das ciências sociais. Rio de Janeiro: Zahar, 1999. p.7-17. 
LOYOLA, M. A. A sexualidade como objeto de estudo das ciências humanas. In:

HEILBORN, M. L. (Org.). Sexualidade: o olhar das ciências sociais. Rio de Janeiro: Zahar, 1999. p.31-39.

MARCUSE, H. A ideologia da sociedade industrial. Tradução de Giasone Rebuá. Rio de Janeiro: Zahar, 1982.

MARWICK, A. Uma história da beleza humana. Tradução de Luiz A. de Araújo. São Paulo: Editora Senac, 2009.

MAUSS, M. As técnicas corporais em Sociologia e Antropologia. São Paulo: EPU: EDUESP, 1974.

NOVAES, J. V. Vale quanto pesa... sobre mulheres, beleza e feiúra. In: CASOTTI, L.; SUAREZ, M.; CAMPOS, R. D. O tempo da beleza: consumo e comportamento feminino, novos olhares. Rio de Janeiro: Senac Nacional, 2008. p.144 - 175

NOVAES, J. V. Ser feia, ser mulher, ser excluída. Psicologia: o portal dos psicólogos, 2005. Disponível em: <http://www.psicologia.com.pt/artigos/textos/A0237.pdf >. Acesso em: 5 ago. 2013.

NUNES, B. Introdução à filosofia da arte. São Paulo: Ática, 2009.

PEREIRA, J. B. B. A linguagem do corpo na sociedade brasileira: do ético ao estético. In: QUEIROZ, R. da S. (Org.). O corpo do brasileiro: estudos de estética e beleza. São Paulo: Editora Senac, 2000. p.67-94.

POUZADOUX, C. Contos e lendas da mitologia grega. São Paulo: Companhia das Letras, 2001.

QUEIROZ, R. da S.; OTTA, E. A beleza em foco: condicionantes culturais e psicobiológicos na definição da estética corporal. In: QUEIROZ, R. da S. (Org.). O corpo do brasileiro: estudos de estética e beleza. São Paulo: Editora Senac, 2000. p.13-66.

ZUIN, A. Á. S. O corpo como publicidade ambulante. Perspectiva: Revista do Centro de Ciências da Educação, Florianópolis, v.21, n.1, p.39-53, jan./ jun. 2003.

\section{Como referenciar este artigo}

OLIVEIRA, Everton Luiz de.; CARDOSO, DENARI, Fátima Elisabeth. O corpo humano como alimento para a sexualidade. Doxa: Rev. Bras. Psicol. Educ., Araraquara, v.19, n.1, p. 67-79, jan./ jun. 2017. ISSN: 1413-2060.

Submetido em: 08/01/2017

Aprovado em: 28/03/2017 